\title{
【研究简报】
}

\section{天文时纬异常与阿根廷San Juan地区的地震活动}

\author{
田静 曾志访 \\ （中国科学院北京天文台, 北京 100080)
}

\section{关钺词 时纬残差 地震 San Juan 天文台}

\section{1 时纬残差的取得及地震资料的选取}

早在唐山地震发生后, 李致森、张国栋等发现强震发生前, 天文测时测纬残差会发生较大 异常 ${ }^{[1]}$. 许多研究表明, 这种现象是一种地震前兆 ${ }^{[2,3]}$. 特别是已有学者利用这一前兆成功 地预报了六次发生在云南天文台附近的中强震 ${ }^{[4,5]}$.

北京天文台的 II 型光电等高仪于 1992 年搬往阿根廷 San Juan 大学天文台执行中国科学 院和阿根廷国家科委的合作项目, 开展全天等高星表及地球动力学的研究工作, 几年来积累 了大量的观测结果. San Juan 地区属地震多发区, 它毗邻 Andes 山脉, 是环太平洋地震带的 一部分. San Juan 天文台原有的一架丹容等高仪一直从事地球自转参数及星表的观测任务. 本文正是取这架仪器 1970 1987 年累计 $17 \mathrm{a}$ 的观测数据处理时纬残差, 研究时纬残差的长 期变化与台站周围地震的活动关系.

光学天文时纬残差是指某架仪器的天文时间和纬度观测值扣除地球自转变化影响后的剩 余部分. 某仪器测时残差 RT 的定义是：

$$
\mathrm{RT}_{i}=\mathrm{UT}_{i}-\mathrm{UT} 1,
$$

(1) 式中 UT1 $i$ 是仪器 $i$ 实际测得的地球自转时, UT1 是由全球时纬仪器测得的地球自转时的平 均值. 因为地球自转速度是变化的,所以依地球自转测得的 UT1 是一种非均匀的时间系统. 国 际地球自转参数服务 (IERS) 定期公布 UT1 - UTC 值, UTC 被认为是足够均匀的原子时系统.

由天文观测直接测得的地球自转时是 $\mathrm{UTO}_{i}, \mathrm{UTO}_{i}$ 加入地极变化造成的地方经度变化 $\Delta \lambda i$ 得到 $\mathrm{UT} 1_{i}$, 即 $\mathrm{UT} 1_{i}=\mathrm{UT} 0_{i}+\Delta \lambda_{i}$, 为使观测资料与 IERS 公布的资料一致, 也应在 UT1 $1_{i}$ 中扣除 UTC, 所以(1)式最终可表示为:

$$
\begin{gathered}
\mathrm{RT}_{i}=\left(\mathrm{RT}_{i}+\Delta \lambda_{i}-\mathrm{UTC}\right)-(\mathrm{UT} 1-\mathrm{UTC}), \\
\Delta \lambda_{i}=\left(X \sin \lambda_{i}-Y \cos \lambda_{i}\right) \operatorname{tg} \Phi_{i} / 15,
\end{gathered}
$$

其中 $X$ 和 $Y$ 为地极坐标的全球综合结果, 它们和 (UT1-UTC)同属于某个地球自转参数系统, 如 国际地球自转参数服务 IERS 系统, $\lambda_{i}$ 和 $\Phi_{i}$ 为该仪器所在地理经纬度. 测纬残差 $\mathrm{RF}_{i}$ 的定义是:

$$
\mathrm{RF}_{i}=\Delta \Phi_{i}-\Delta \Phi,
$$

(2) 式中 $\Delta \Phi_{i}$ 是仪器 $i$ 实际测得的该观测点的纬度变化, $\Delta \Phi$ 是地极移动形成的纬度变化.

$$
\Delta \Phi=X \cos \lambda_{i}+Y \sin \lambda_{i} .
$$

$\mathrm{RT}_{i}$ 和 $\mathrm{RF}_{i}$ 一般不等于零, 在一定范围内波动. 这种波动主要是观测点地方性因素引起的. 地方性因素主要包括：（1）大气的反常折射; (2)地方性的垂线变化; (3)观测点的水平位移. 大 气的反常折射可以用经验公式消除, 而地方性的垂线变化及观测点的水平位移都可能是台站附 
近地震的前兆. 地下物质, 特别是易于流动的地下水在地震前剧烈运动从而造成重力场变化的 震例很多. 模拟计算表明, 对震中一定距离的光学天测仪器, 地球重力场水平分量的变化能较好 地解释地震前后天文时纬残差的异常波动 ${ }^{[6,7]}$. 李致森、韩延本等 ${ }^{[8]}$ 研究了数架仪器时纬残差短 期变化 (10 a 以下) 和地震的关系, 发现大震前 $(M \geqslant 5.0)$ 时纬残差会出现较大异常, 其机制可以 用垂线变化来解释; 田静 ${ }^{[9]}$ 研究了位于全球主要地震带上的 5 架时纬仪器测时测纬的长期变化 (大于 $10 \mathrm{a}$ ), 其结论与短期变化有别, 南半球的地震多发生在测纬残差曲线的顶部, 而北半球的 地震多发生在谷部, 这一结论可以归纳为, 对时纬残差的长期变化而言, 地震多发生在测站纬度 减小的时候, 即测站向赤道方向位移最大的时候, 这一现象的机制可以用观测点的水平位移解 释. 本文所用的资料较文献 [9]所用的资料有了很大改进, 主要是时间域大为延长, 资料处理的 方法也有所改进.

发生在 San Juan 地区附近 $400 \mathrm{~km}$ 以内, 震级大于 6.0 的地震 $(1971 \sim 1987)$ 共有 13 个. 对发生在同一天的主震和余震 (或前震), 或日期间隔在三个月内的地震群, 只考虑震级最大的 主震, 舍掉前震和余震. 经过这样取舍之后的地震共有 10 个.

\section{2 地震与时纬残差曲线的对应结果}

通过以上处理的 10 个地震以及与时纬残差的对应情况见表 1 .

表 1 San Juan 附近的地震与时纬残差的对应关系 ${ }^{\mathrm{a}}$

\begin{tabular}{|c|c|c|c|c|c|c|c|c|}
\hline \multirow{2}{*}{ 序号 } & \multirow{2}{*}{ 日期 } & \multicolumn{2}{|c|}{ 霞中位置 } & \multirow{2}{*}{ 䈨级 } & \multirow{2}{*}{$\begin{array}{l}\text { 震源深 } \\
\text { 度 } / \mathrm{km}\end{array}$} & \multirow{2}{*}{$\begin{array}{l}\text { 与 San Juan } \\
\text { 朢离/km }\end{array}$} & \multirow{2}{*}{$\mathrm{RF}$} & \multirow{2}{*}{ RT } \\
\hline & & 纬度 & 经度 & & & & & \\
\hline 1 & $1971-07-09$ & $32.5 \mathrm{~S}$ & $71.2 \mathrm{~W}$ & 7.9 & 58 & 278 & 顶 & $\star$ \\
\hline 2 & $1972-06-08$ & $30.5 \mathrm{~S}$ & $71.8 \mathrm{~W}$ & 7.1 & 36 & 324 & 谷 & 顶 \\
\hline 3 & $1972-09-26$ & $30.9 \mathrm{~S}$ & $68.1 \mathrm{~W}$ & 6.1 & 16 & 77 & 顶 & $\star$ \\
\hline 4 & $1972-12-29$ & $30.5 \mathrm{~S}$ & $71.1 \mathrm{~W}$ & 6.0 & 61 & 272 & 顶 & 顶 \\
\hline 5 & $1973-10-05$ & $33.0 \mathrm{~S}$ & $71.9 \mathrm{~W}$ & 6.9 & 14 & 361 & 顶 & $\star$ \\
\hline 6 & $1975-03-13$ & $29.5 \mathrm{~S}$ & $71.2 \mathrm{~W}$ & 6.9 & & 341 & 顶 & 顶 \\
\hline 7 & $1977-11-23$ & $31.2 \mathrm{~S}$ & $67.8 \mathrm{~W}$ & 7.4 & 4 & 74 & 顶 & 谷 \\
\hline 8 & $1980-07-19$ & $28.9 \mathrm{~S}$ & $69.5 \mathrm{~W}$ & 6.7 & 110 & 305 & 顶 & 顶 \\
\hline 9 & $1981-11-07$ & $33.0 \mathrm{~S}$ & $72.0 \mathrm{~W}$ & 7.0 & & 369 & $\star$ & 顶 \\
\hline 10 & 1985-04-09 & $34.0 \mathrm{~S}$ & $71.0 \mathrm{~W}$ & 7.4 & 33 & 364 & 谷 & $\star$ \\
\hline
\end{tabular}

a) \代表地震发生在残差曲线的非顶非谷段

图 1 所示是 San Juan 天文台的时纬残差图, 其中箭头表示地震的发生时间. 从图 1(b) 可以 看出, 10 个地震中有 7 个发生在 RF 曲线的顶段, 占总数的 $70 \%$; 有两个发生在谷段, 有一个发生 在非顶非谷段. 在 RF 曲线的顶段, 其意义是观 测地纬度向北 (即赤道方向)发生最大偏移. 这一 结论与北半球的情况相同 ${ }^{[9]}$, 即北半球的地震多 发生在纬度向南(即赤道方向)偏移最大的时候。

San Juan 附近的地震与测时残差 RT 的关系 类似于与 RF 的关系(图 1(a)). 在所研究的 10 个地震中, 有 5 个发生在 RT 曲线的顶段, 一个发

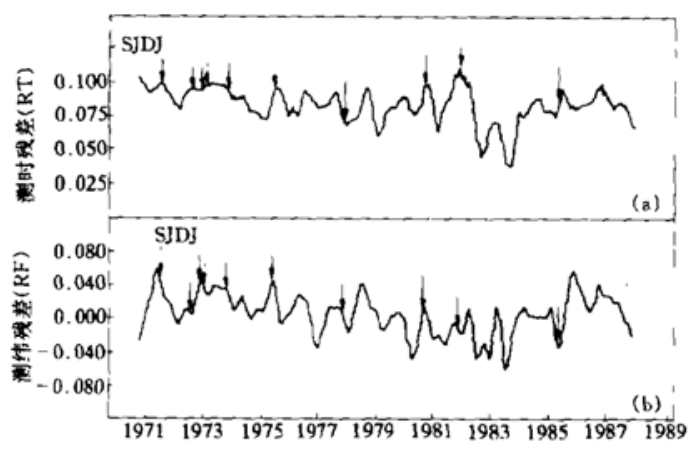

图 1 San Juan 地震与丹容等高仪测时 (a)测纬 (b) 残差的关系 
生在谷段, 4 个发生在非顶非谷段. 这一结论与以往的研究结果相似, 即地震与测时残差的关 系不如与测纬残差的关系强烈. 其实, 对某一观测点来说, 当地的地质构造对地震与时纬残差 的相关情况有重要影响. 由于测纬残差表现的是重力场南北方向的变化, 而测时残差是东西 方向的变化, 所以, 如果地震前震源附近的物质分布出现某一方向明显的变化时, 表现在时纬 残差中就是其中一项强于另一项.

\section{3 结果讨论}

上面已经提到过, 引起时纬残差的主要因素即地方性的垂线变化和观测点的水平位移都可 以引起地震前时纬残差的变化. 时纬观测的基准线是地方铅垂线. 地震前由于地下物质的运 动, 导致铅垂线的方向发生变化, 这种变化反映在时纬残差的变化中, 是时纬残差变化的一部分 因素. 另一部分因素是震前观测点附近地壳水平位移. 模拟计算表明 ${ }^{[7]}$, 垂线变化引起的测纬 残差 RF 的最大值为 0. . 06 , 而 San Juan 天文台的 RF 最大值可达 0. . 07 , 也就是说, 观测点的水平 位移引起的 RF 可达 $0 . .^{\prime \prime} 01$, 相应地壳形变的量级是 $10^{-7}$, 这个数值接近实测数值 ${ }^{[10]}$. 就垂线变 化和水平位移这两个引起时纬残差的因素进行比较, 水平位移引起的测纬残差量级较小.

我们所研究过的南北两个半球的震例都是发生在地壳向赤道方向移动的时候, 这不是偶 然的, 是有其物理背景的. 当地球自转时, 它上面的每一点都要受到惯性离心力的作用, 这个 力可以分解为背向地心的力和指向赤道的力. 这个指向赤道的力使每一点有向赤道方向发生 位移的趋势. 在一般情况下, 地壳不受外力时处于平衡状态, 指向赤道的力不会使地壳向赤道 发生位移. 当有水平应力积累时, 地壳最易发生形变的方向是隆起 (这种隆起已在许多震例中 被观测到). 当地壳隆起时, 岩石强度会降低, 在指向赤道力的激发下, 就很容易向赤道发生位 移了. 当地震发生时, 也正是位移最大时, 震后则位移减小, 回复正常.

事实上, 我们所研究过的震例大多发生在 RF 曲线的底部(对北半球而言), 如果我们只用垂 线变化去解释这种现象, 则不够全面, 应该加上水平位移的影响, 虽然它比垂线变化的影响要小.

\section{参文 嶰}

1 李致森, 张国栋, 张换志, 等. 天文测时测纬的一种短时间异常与台站附近强震的对应关系. 地球物理学报, 1978, 21 (4) : $278 \sim 291$

2 Li Zhisen, Han Yanben. A possible geophysical interpretation of the anomalies in residuals of astronomical time and latitude determinations. Vistas in Astronomy, 1988, 31 : 671 675

3 Han Yanben. Short-period anomalous fluctuations of astronomical time and latitude and vertical line variations before major earthquake. Wiss Z Techn Univers, 1989, 38: 43 44

4 胡裙, 李水生, 壬锐, 等. 云南天文台时纬残差与昆明周围地震. 地球物理学报, 1988,31(4): 483 485

5 胡 解, 阔荣举. 时纬残差分析方法及残差变化与强震的相关性. 地震研究, 1989, 12(3): 277 283

6 张国栋. 强震前地下水活动引起的垂线变化. 地震学报, 1981,3(2): 152 - 158

7 曾志访. 地下水异常体模型反演天文时纬残差异常. 见: 中国科协天地生综合研究联络组编。天地生综合研究进展. 北京: 中国科学技术出版社, 1989.290 295

8 Li Zhisen, Han Yanben, Tian Jing. A possible geophysical interpretation of the anomalies in the residuals of astronomical time and latitude determination. Astrophysics and Space Science, 1991, 177, 377 382

9 Tian Jing. The long period changes in astronomical latitude residuals and the major earthquakes around the observatories. Publ of Beijing Astro Obser, 1989. 110 - 116

10 胡明帔,鲁 福. 现代大地测量学. 北京: 测绘出版社, 1994.831

(1996-12-11 收稿, 1997-06-02 收修改稿) 